\title{
CHRONIC NEONATAL DIAZOXIDE THERAPY IS NOT ASSOCIATED WITH ADVERSE EFFECTS
}

\author{
${ }^{1}$ Michele M. Cox, ${ }^{1}$ Christopher C. Wendler, ${ }^{2}$ Ildiko Erdelyi, \\ ${ }^{2}$ Amanda Beck, ${ }^{2}$ Caroline Zeiss and ${ }^{1}$ Scott A. Rivkees \\ ${ }^{1}$ Department of Pediatrics, University of Florida, College of Medicine, Gainesville USA \\ ${ }^{2}$ Department of Comparative Medicine and Ophthalmology, Yale University, New Haven
}

Received 2013-10-25; Revised 2014-01-17; Accepted 2014-01-27

\begin{abstract}
Diazoxide is an ATP-sensitive potassium channel $\left(\mathrm{K}_{\mathrm{ATP}}\right)$ agonist that has been shown to neuroprotective effects. These observations raise the possibility that diazoxide may have potential as a therapeutic agent for other applications. This study investigated (1) the long term effects of chronic neonatal administration of diazoxide and (2) the role of $\mathrm{K}_{\mathrm{ATP}}$ on murin behavior and neurohistology. $\mathrm{C} 57 \mathrm{~B} / 6 \mathrm{~J}$ pups were injected daily with diazoxide $\left(10,20\right.$ or $50 \mathrm{mg} \mathrm{kg}^{-1}$ ) or vehicle from Postnatal days 2 (P2) through P12. Pups were allow to mature and underwent behavioral testing at 5-7 months of age. After behavioral testing, animals were euthanized and morphology of the brains was assessed. No long term adverse effects of neonatal diazoxide therapy on physical characteristics, visual acuity, sensori-motor reflexes, spontaneous locomotor activity, motor coordination/balance or motor learning and memory were observed. In addition, no morphological changes were observed on brains. However, we did observe that diazoxide therapy causes depressive-like phenotypes in female murine mice. Chronic neonatal diazoxide therapy does not cause deficits or enhancements in mice behavior. Diazoxide does not cause abnormal morphological changes in brain anatomy. However, diazoxide does cause gender specific depressive-like phenotype in mice.
\end{abstract}

Keywords: Diazoxide, Behavior, Depression, Forced Swim

\section{INTRODUCTION}

ATP-sensitive potassium $\left(\mathrm{K}_{\mathrm{ATP}}\right)$ channels are expressed in a variety of cell types including neurons, astrocytes and vascular endothelial cells. In addition, $\mathrm{K}_{\text {ATP }}$ channels have been shown to regulate numerous physiological processes (Ashcroft and Ashcroft, 1990). Much attention has been focused on the potential therapeutic function of $\mathrm{K}_{\mathrm{ATP}}$ channels-to preserve the viability cells or impede cell death in various experimental models. Specifically, pharmacological activation of the mitoK $\mathrm{K}_{\text {ATP }}$ using diazoxide, exerts a protective effect on cardiac cells, neurons in the brain against ischemic damage and death in experimental models of myocardial infarction (Baines et al., 1999; Murata et al., 2001; Takashi et al., 1999; Zaugg et al., 2002) and stroke(Lui et al., 2002). Additional studies have Stroke(Lui et al., 2002). Additional studies have FDA as a treatment for hyperinsulinism, may have Tell: (352) 273-9001 Fax: (352) 294-5247 demonstrated the protective role of diazoxide on hypoxia-ischemia-reperfusion in cultured hippocampal neurons and gerbil brain (Wang et al., 2011), in cultured hippocampal and cortical neurons against hypoxic and oxidative injury (Liu et al., 2003) and A $\beta$ toxicity (Goodman and Mattson, 1996). In mice, using chronic sublethal hypoxia as a model of PWMI, we observed that diazoxide markedly reduces hypomyelination, which is associated with PWMI (Fogal et al., 2010). Specifically, we observed, that Oligodendrocyte Precursors (OPC) cultured in hypoxic conditions had reduced OPC proliferation which was reverse with diazoxide by stimulating OPC proliferation (Fogal et al., 2010).

These observations raise the possibilities that diazoxide, currently approved for use in children by the FDA as a treatment for hyperinsulinism, may have 
potential clinical utility in other aspects. Diazoxide activates mitochondrial $\mathrm{K}_{\mathrm{ATP}}\left(\right.$ mitoK $\left._{\mathrm{ATP}}\right)$ channels that consist of two structurally diverse subunits. One subunit is a member of the pore-forming inward rectifier Kir6.x family of potassium channels, while the other subunit is a Sulfonylurea Receptor (SUR) that belongs to the ATP-binding cassette superfamily (Babenko et al., 1998; 2000).

By employing diazoxide we had two main objectives in this study. First, we thought it worthwhile to investigate the long-term effects of neonatal diazoxide therapy on behavior and morphology and 2) better elucidate the role of $\mathrm{K}_{\mathrm{ATP}}$ channels on behavior and morphology.

\section{METHODS AND MATERIALS}

\subsection{Animals}

All procedures related to animals were performed in accordance with Yale University Institutional Animal Care and Use Committee and University Laboratory Animal Resources policies and guidelines. Adult male and female C57B/J6 mice were obtained from Charles River Laboratories (Wilmington, MA). Mice were housed in same sex cages and maintained in a temperature/humidity controlled room $12 \mathrm{~h} \mathrm{light/dark} \mathrm{cycle.} \mathrm{Mice} \mathrm{had} \mathrm{access} \mathrm{to}$ food and water ad libitum. Timed matings were performed. Females were checked daily for the presence of copulation plugs. Once identified, females were separated from the males, the day vaginal plug was found designated as gestation day $0(\mathrm{G}) 0$.

Mice were weaned at postnatal day 21 (P) 21. Behavioral testing was performed at 5-7 month of age because previous short-term studies demonstrated that chronic diazoxide therapy did not cause any behavioral changes. Animals were allowed to acclimate to the testing room for approximately $1 \mathrm{~h}$ before behavioral testing was performed. Animals were naïve to behavioral testing prior to the tests described. The investigator, performed behavioral tests was not aware of treatments. The present study was conducted on $(2$ treatments $) \times(2$ genders $)=(4$ groups) of 8-14 mice each.

\subsection{Drug Preparation and Administration}

Diazoxide (Tocris) was initially dissolved in dimethyl sulfoxide (DMSO; Sigma) to a final concentration of 20 $\mathrm{mg} \mathrm{mL} \mathrm{m}^{-1}$. Stock solution (with and without drug) were diluted in Buffer Saline (D-PBS; Invitrogen) prior to injection for drug and vehicle-control injections. C57B/J6 pups were given a single injection daily in the nape of the neck with either vehicle or diazoxide $(10,20,50$ or 100 $\mathrm{mg} \mathrm{kg}^{-1}$ ) from $\mathrm{P} 2$ to $\mathrm{P} 12$. This age period is equivalent to the vulnerable period of PWMI (Back and Rivkees, 2004; Craig et al., 2003). In preliminary studies, the dose of 100 $\mathrm{mg} \mathrm{kg}^{-1}$ of diazoxide caused death in $84 \%$ of mice and therefore was not used. Individual daily doses per pup were based on the average litter weight per cage.

\subsection{Experimental Behavioral Procedures}

\subsubsection{Physical and Neurological Screening}

The physical and neurological screening tests performed as previously described (Cox et al., 2009). Briefly, each mouse was weighed, placed in an empty cage and observed for 3 min. A number of physical characteristics, including poor grooming, bald spots, absence of whiskers, labored breathing porphyrin staining, were characterized and recorded. Several behavioral activities were assessed including, jumping, sniffing, rearing, approach to object, movement throughout the cage, urination and defecation. Visual acuity was assessed by placing each mouse on a visual cliff platform (28 cm above the ground) for $2 \mathrm{~min}$. Behavioral responses such as, approach to edge and poking nose over the edge were recorded. Sensorimotor reflexes (stabilization, righting, eye blink, ear touch and whisker touch) were evaluated and recorded. The animals' behaviors during screenings were scored qualitatively in real time. In our previous we have not observed hyperglycemia in comparably-treated mice and therefore did not test hyperglycemia. In addition, a key symptom of hyperglycemia is increased body weight, therefore body weights were measured before and after behavioral testing.

\subsubsection{Open Field Exploration}

Spontaneous locomotor activity and anxiety-like phenotypes were evaluated using the open field exploration test, as described previously (Cox et al., 2009). The Plexiglass chamber $(28.2 \times 28.2 \times 27.2 \mathrm{~cm})$ was cleaned before and between testing with $70 \%$ ethanol. A video camera was mounted directly above the apparatus. The field was divided into two regions of interest: 1 ) center area $(5 \times 5 \mathrm{~cm})$ and 2) peripheral area (Noldus EthoVision XT version 8, Wageningen, The Netherlands). Two lamps with $60 \mathrm{~W}$ light bulbs were the only light sources in the room, providing an illumination intensity of 8 lux in the center of the open field. Mice were placed in the center of the open field and allowed to move freely for $12 \mathrm{~min}$. The total distance traveled and 
the time spent in the brighter center (which tends to be aversive to mice) were recorded automatically using the Noldus EthoVision XT tracking system. An adverse effect of diazoxide therapy is hypotension, it was not possible to assess blood pressure in tmouse pups and therefore could not determine if mice had hypotension at the time of drug administration. Hypotension is associated with motor deficits which were measured using the open field exploration test.

\subsubsection{Rotarod}

Motor coordination/balance and motor learning and memory were assessed using an accelerating rotarod (AccuScan Instruments, Inc., Columbus, OH). Mice were habituated as described (Cox et al., 2009) to the rotating rod at a constant speed of 4 rotations per minute (rpm) for $5 \mathrm{~min}$, during which time latency to fall was not recorded. If a mouse fell off the apparatus, it was quickly placed back on top of the rod until the 5 min trial was completed. The habituation trial was only performed on the first day. Mice were subsequently exposed to a rotating rod starting at $4 \mathrm{rpm}$ and linearly accelerating to $40 \mathrm{rpm}$ over a period of $5 \mathrm{~min}$. Mice were given three trials per day with a maximum time per trial of $5 \mathrm{~min}$ and $30 \mathrm{~min}$ inter-trial rest interval for 5 consecutive days. The rotarod was cleaned prior to testing and between animals with $70 \%$ ethanol. If a mouse reached the latency of $5 \mathrm{~min}$ without falling the trial was ended. Mice were tested at approximately the same time every day for 5 consecutive days and performances in daily trials were averaged for data analysis.

\subsubsection{Porsolt Forced Swim}

Depressive-like phenotypes were measured using the Porsolt forced swim test, as described (Porsolt et al., 1977). Mice were placed in cylindrical beakers filled with $10 \mathrm{~cm}$ of water for $5 \mathrm{~min}$. The water temperature was between 21 and $24^{\circ} \mathrm{C}$. A video camera was mounted directly above beaker to record mouse activity (Noldus EthoVision XT version 8, Wageningen, The Netherlands). The total duration of immobility (total amount of time animal is immobile during the 5 minute session) and latency to immobility (how much time it takes before the animal to gives up searching for an escape route) were recorded automatically using Noldus EthoVision XT tracking system. Immobility was defined as the absence of movement, unless they are necessary for the animal to stay afloat (head above water). After testing, mice were placed on warming mats before being returned to their cages.

\subsection{Behavioral Analysis}

Open field and Porsolt forced swim tests were videotaped using an Everfocus EQ-610, CDD video camera mounted above the apparatuses and video tracked using Noldus EthoVision XT version 8. The system recorded total distance traveled and time spent in defined areas for the open field. For Porsolt forced swim test, total distance traveled, total duration of immobility and swim speed were recorded. Raw data were analyzed using the Noldus EthoVision XT version 8 software (Noldus Information Technology).

\subsection{Histopathology}

After behavioral testing was completed, body weight was measured and mice were euthanized by $\mathrm{CO}_{2}$ inhalation. Calvarium was opened, brains weighed and immersed in Bouins' solution. Brains were evaluated by Mouse Research Pathology laboratory in the Section of Comparative Medicine at Yale University. Coronal sections were cut at 8 levels: (1) olfactory bulb, frontal and pyriform cortex; 2 and 3 septo-striatal (basal nuclei) to septo-diencephalic; 4 and 5 rostral to caudal diencephalon (thalamus, hypothalamus, hippocampus); 5 and 6 rostral to caudal mesencephalon; 7 rostral cerebellum and brainstem; (8) caudal cerebellum and brainstem. Sections were embedded in paraffin for processing, cut at $5 \mu \mathrm{m}$ and stained with Hematoxylin and Eosin (H\&E). Histologic sections were examined by light microscopy using a Zeiss Axioscope by a pathologist masked to treatment.

\subsection{Statistical Analysis}

Data were analyzed using Graphpad Prism 5.0 for Windows (San Diego, CA). Normality of the data for each variable was determined using the D'Agostino and Pearson test. All data were analyzed using one-way Analysis of Variance (ANOVA) followed by Sidak's multiple post hoc comparison or Kruskal-Wallis test followed by Dunn's multiple post hoc comparison. Rotarod data were analyzed using two-way ANOVA with repeated measure followed by Bonferroni's multiple post hoc comparison. All data presented as mean \pm SEM. For all analyses, statistical significance was defined as $\mathrm{p} \leq 0.05$.

\section{RESULTS}

To assess the long term safety of diaoxide, C57B/J6 pups were given a single injection daily of vehicle or diazoxide $\left(10,20\right.$, or $\left.50 \mathrm{mg} \mathrm{kg}^{-1}\right)$ from P2 to P12. Mice 
were weaned at P 21, behavioral tests were performed on both male and females at 5-7 months of age.

\subsection{Physical and Neurological Screening}

To assess neuromuscular function, sensori-motor function and visual acuity, mice underwent physical and neurological screenings. No qualitative differences in physical characteristics, visual acuity or sensori-motor reflexes were observed for any treatment $\left(10,20\right.$ or $\left.50 \mathrm{mg} \mathrm{kg}^{-1}\right)$.

In addition to the above tests, body weight was examined. Multiple one-way ANOVAs or KruskalWallis tests followed by post hoc multiple comparisons revealed a no significant effect of treatment on body weight for same sex animals. There was significant effect of gender on body weight, as females in all treatment groups had significantly lower weight than males as expected $\left(10 \mathrm{mg} \mathrm{kg}^{-1}\right.$ treatment group $\mathrm{p}=0.0074$, data not shown; $20 \mathrm{mg} \mathrm{kg}^{-1}$ treatment group $\mathrm{p}<0.0001$, data not shown; $50 \mathrm{mg}$ $\mathrm{kg}^{-1}$ treatment groups $\mathrm{p}<0.0001$, data not shown).

\subsection{Open Field Exploration}

To measure hyperactivity and general spontaneous locomotor activity, total distance traveled was evaluated on the open field exploration apparatus. Kruskal-Wallis test revealed no significant effect of treatment on locomotor activity for the $10 \mathrm{mg} \mathrm{kg}^{-1}$ treatment group ( $\mathrm{p}=$ 0.0924; Table 1 and 2, respectively). Post hoc multiple comparison did not show any significant effect of gender. One-way ANOVA demonstrated no statistically significant effect of treatment on locomotor activity in $50 \mathrm{mg} \mathrm{kg}$ treatment group (and $\mathrm{F}_{[3,47]}=1.692, \mathrm{p}=$ 0.1815; Table 1 and 2, respectively). In addition, post hoc comparison revealed no significant effect of gender. However, the Kruskal-Wallis did show significant effect of treatment for the $20 \mathrm{mg} \mathrm{kg}^{-1}$ treatment group $(p=0.001)$. Analysis revealed that diazoxide-treated females traveled significantly less than their vehicle-control counterparts Table 2. Similar results were not observed between vehicle-control and diazoxide-treated males Table 1.

To assess anxiety-like phenotypes the total time spent in the center of the field was measured. All treatment groups exhibited a clear preference for the periphery of the open field chamber. One-way ANOVA and Kruskal-Wallis tests demonstrated no significant effect of treatment on the total time spent in the center of open field for 10,20 or $50 \mathrm{mg} \mathrm{kg}^{-1}$ treatment groups $\left(\mathrm{F}_{[3,35]}=1.898, \mathrm{p}=0.1479, \mathrm{~F}_{[3,52]}=0.8159, \mathrm{p}=0.4190\right.$ and $\mathrm{p}=0.6380$, respectively; Fig. 1) In addition, multiple comparison tests revealed no significant effect of gender on total time spent in the center of the open field for any treatment group.

\subsection{Rotarod}

To assess motor coordination/balance and motor learning and memory, mice were evaluated on an accelerating rotarod. The performance of $20 \mathrm{mg} \mathrm{kg}^{-1}$ and $50 \mathrm{mg} \mathrm{kg}^{-1}$ treatment groups improved over the five days training. Two-way ANOVA with repeated measures of the $20 \mathrm{mg} \mathrm{kg}^{-1}$ treatment group showed a significant effect of gender and time between diazoxide-treated females and their male-counterparts only $\left(\mathrm{F}_{[1,34]}=33.26\right.$; $\mathrm{p}=0.0001$ and $\mathrm{F}={ }_{[4,136]}=17.35 ; \mathrm{p}<0.0001$, respectively). In addition, student t-test demonstrated a significant effect of treatment on performance between vehicle and diazoxide-treated females from day 3-day 5 $(\mathrm{p}<0.05$ Day 3, $\mathrm{p}<0.05$ Day 4 and $\mathrm{p}<0.001$ Day 5; Fig. 2 . Similar results were not observed between vehicle and diazoxide-treated males.

Analyses demonstrated that there was significant effect of time between vehicle-control females or diazoxide-treated females and their male-counterparts $\left(\mathrm{F}_{[4,100]}=21.54 ; \mathrm{p}<0.001\right.$ and $\mathrm{F}_{[4,80]}=27.11 ; \mathrm{p}<0.0001$, respectively). Examination of the $50 \mathrm{mg} \mathrm{kg}^{-1}$ treatment groups revealed a significant effect of gender, with females performing better than their male counterparts $\left(\mathrm{F}_{[1,25]}=2003 ; \mathrm{p}=0.0001\right.$ (vehicle) and $\mathrm{F}=_{[1,20]}=$ $6.240 ; \mathrm{p}=0.0213$ (diazoxide). In addition, student's ttest revealed a significant effect of treatment on performance between vehicle and diazoxide-treated females on the final day of testing $(\mathrm{p}<0.05$; Fig. 3 . Similar results were not observed between vehicle and diazoxide-treated males.

\subsection{Porsolt Forced Swim}

To evaluate depressive-like phenotypes duration of immobility was evaluated on the Porsolt forced swim apparatus. Analysis duration of immobility using Kruskal-Wallis and one-way ANOVA revealed no significant effect of treatment for 20 or $50 \mathrm{mg} \mathrm{kg}^{-1}$ (p $=0.2162$ and $\mathrm{F}_{[3,47]}=0.1908, \mathrm{p}=0.9022$, respectively; Fig. 4. One-way ANOVA demonstrated a significant effect of treatment on duration to immobility from the $10 \mathrm{mg} \mathrm{kg}$ treatment group was shown $\left(\mathrm{F}_{[3,36]}=\right.$ 4.434, $\mathrm{p}=0.0094$. Post hoc multiple comparison analysis showed that diazoxide-treated females had longer duration of immobility than their vehicle-control counterparts $(p<0.05$. Similar results were not observed for between diazoxide-treated males and their vehiclecontrol counterparts. Analysis also revealed no significant effect of gender for any treatment group. 

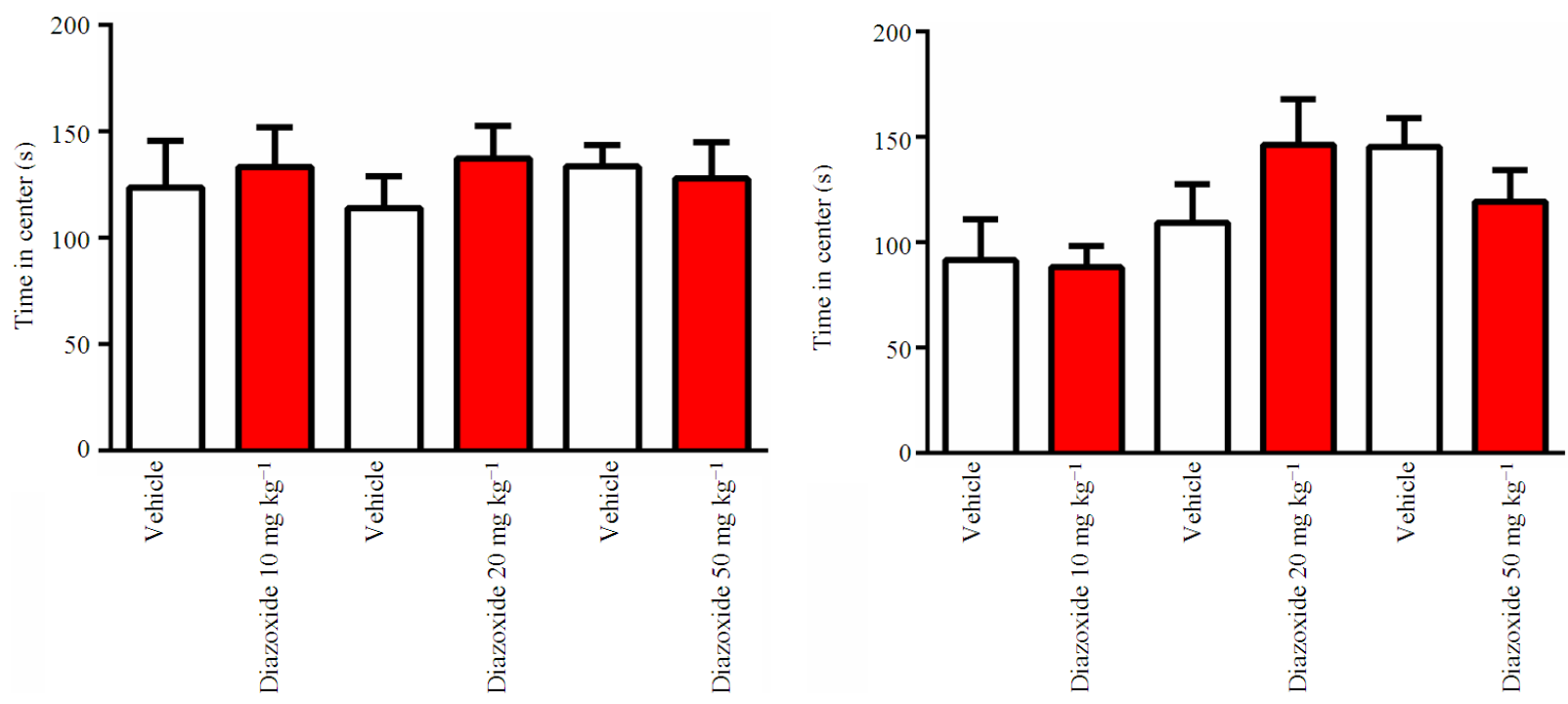

Fig. 1. Open field exploration total time spent in center: Total time (s) spent in the center of the open field during twelve minute session for vehicle Vs. diazoxide at all treatments (top; Female (F) and bottom; male). Analyses performed using one-way ANOVA or Kruskal-Wallis test. $\left(10 \mathrm{mg} \mathrm{kg}^{-1} \mathrm{n}=8\right.$ vehicle $(\mathrm{F}), \mathrm{n}=8$ vehicle $(\mathrm{M}), \mathrm{n}=10$ diazoxide (F) and $\mathrm{n}=13$ diazoxide (M); $20 \mathrm{mg} \mathrm{kg}^{-1} \mathrm{n}=11$ vehicle $(\mathrm{F}), \mathrm{n}=9$ vehicle $(\mathrm{M}), \mathrm{n}=17$ diazoxide $(\mathrm{F})$ and $\mathrm{n}=19$ diazoxide $(\mathrm{M}) ; 50 \mathrm{mg} \mathrm{kg}^{-1} \mathrm{n}=14$ vehicle $(\mathrm{F}), \mathrm{n}=13$ vehicle $(\mathrm{M}), \mathrm{n}=14$ diaozixde $(\mathrm{F})$ and $\mathrm{n}=10$ diazoxide $(\mathrm{M}))$.
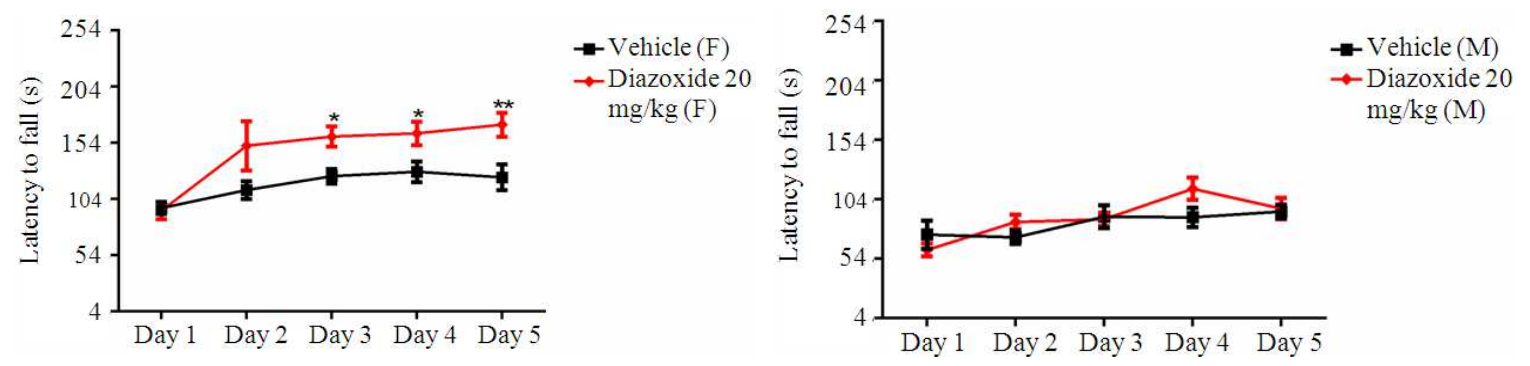

Fig. 2. Rotarod Performance Daily Latencies to Fall: Improvement in the latency to fall as mice managed to stay atop accelerating rotarod over 5 consecutive days with 3 trials per day for vehicle Vs. diazoxide (20 mg kg-1) (top) Female (F) and (bottom) Male (M). Analyses performed using multiple two-way ANOVA with repeated measures. $n=11$ vehicle $(F), n=9$ vehicle (M), $\mathrm{n}=17$ diazoxide $(\mathrm{F})$ and $\mathrm{n}=19$ diazoxide $(\mathrm{M}) ;{ }^{*} \mathrm{p}<0.05$
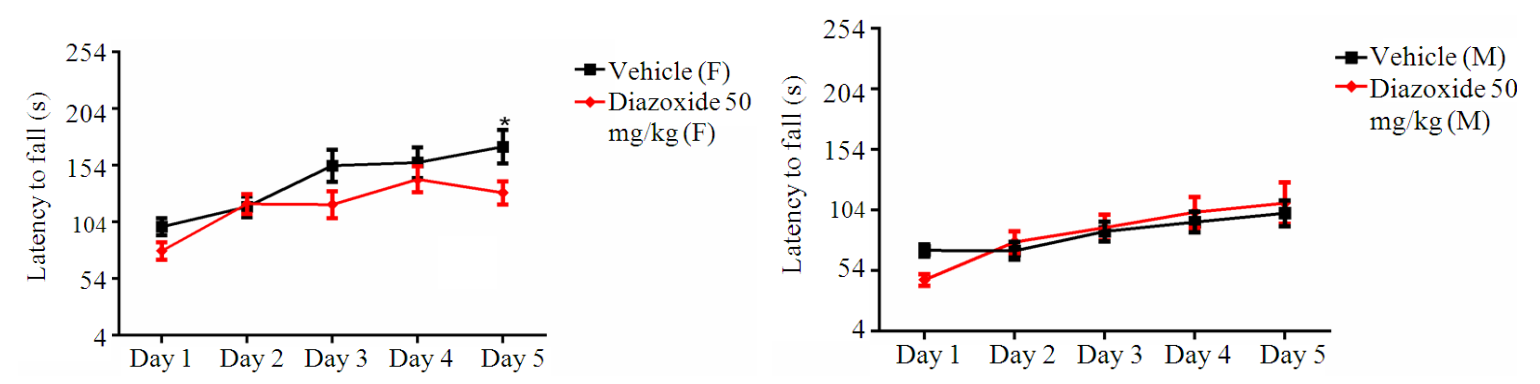

Fig. 3. Rotarod performance daily latencies to fall: Improvement in the latency to fall as mice managed to stay atop accelerating rotarod over 5 consecutive days with 3 trials per day for vehicle Vs. diazoxide $\left(50 \mathrm{mg} \mathrm{kg}^{-1}\right)$ (top) female (F) and (bottom) male (M). Analyses performed using multiple two-way ANOVA with repeated measures and student $\mathrm{t}$ test for individual daily comparisons. [50 $\mathrm{mg} \mathrm{kg}^{-1} \mathrm{n}=14$ vehicle (F), $\mathrm{n}=13$ vehicle $(\mathrm{M}), \mathrm{n}=14$ diaozixde $(\mathrm{F})$ and $\mathrm{n}=10$ diazoxide $\left.(\mathrm{M})\right] .{ }^{*} \mathrm{p}<0.05, * * \mathrm{p}<0.001$ 

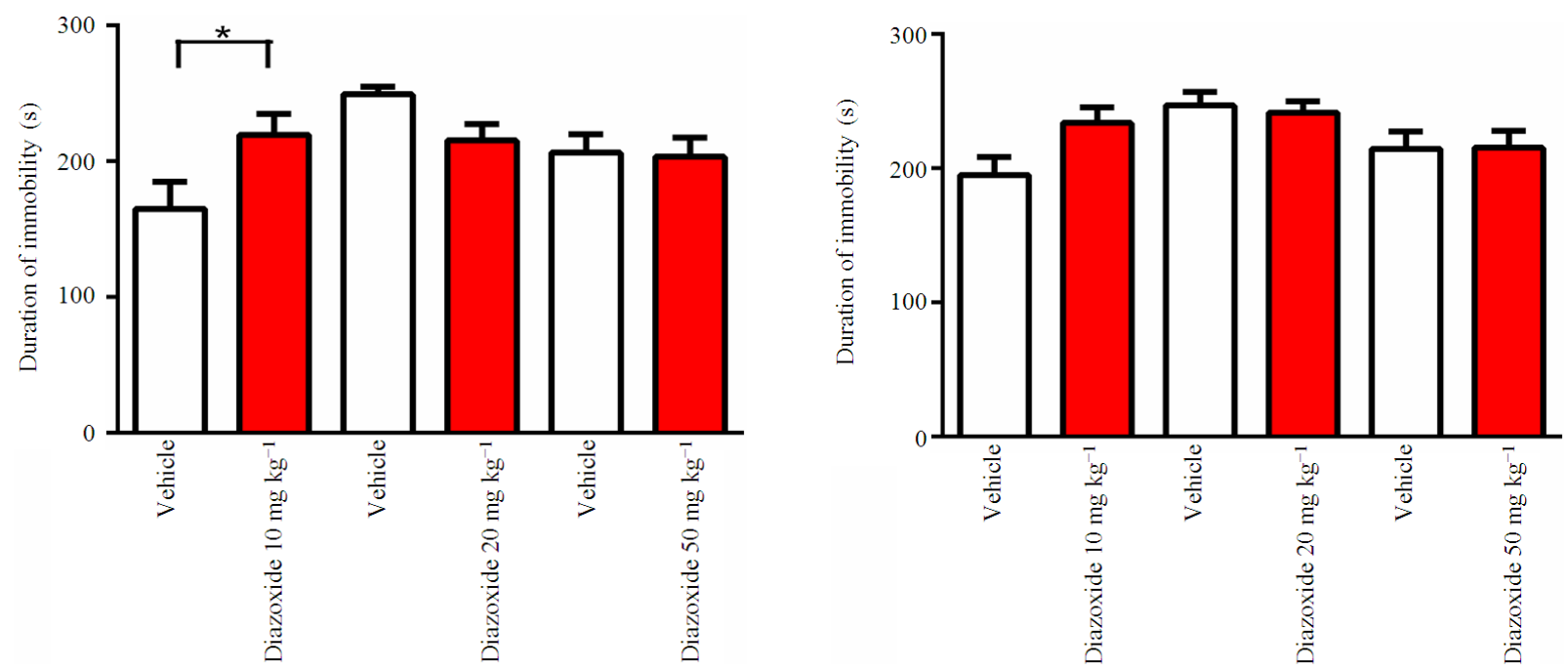

Fig. 4. Porsolt forced swim total duration of immobility: Total duration mice were immobile in (s) during 5 min session. Analyses performed using Kruskall-Wallis or one-way ANOVA tests. $\left(10 \mathrm{mg} \mathrm{kg}^{-1} \mathrm{n}=8\right.$ vehicle $(\mathrm{F}), \mathrm{n}=8$ vehicle $(\mathrm{M}), \mathrm{n}=10$ diazoxide $(F)$ and $n=13$ diazoxide $(M) ; 20 \mathrm{mg} \mathrm{kg}^{-1} \mathrm{n}=11$ vehicle $(\mathrm{F}), \mathrm{n}=9$ vehicle $(\mathrm{M}), \mathrm{n}=17$ diazoxide $(\mathrm{F})$ and $\mathrm{n}=19$ diazoxide $(\mathrm{M}) ; 50 \mathrm{mg} \mathrm{kg}^{-1} \mathrm{n}=14$ vehicle $(\mathrm{F}), \mathrm{n}=13$ vehicle $(\mathrm{M}), \mathrm{n}=14$ diaozixde $(\mathrm{F})$ and $\mathrm{n}=10$ diazoxide $(\mathrm{M})$ ).

Table 1. Total distance traveled in the open field during welve minute session (Males)

\begin{tabular}{|c|c|c|}
\hline Treatment & Gender & Distance traveled $(\mathrm{m})$ \\
\hline Vehicle & Male & $24.41 \pm 1.770$ \\
\hline Diazoxide & & \\
\hline$\left(10 \mathrm{mg} \mathrm{kg}^{-1}\right)$ & Male & $28.02 \pm 0.9244$ \\
\hline Vehicle & Male & $23.97 \pm 2.868$ \\
\hline Diazoxide & & \\
\hline$\left(20 \mathrm{mg} \mathrm{kg}^{-1}\right)$ & Male & $26.08 \pm 1.348$ \\
\hline Vehicle & Male & $20.51 \pm 1.411$ \\
\hline $\begin{array}{l}\text { Diazoxide } \\
\left(50 \mathrm{mg} \mathrm{kg}^{-1}\right)\end{array}$ & Male & $21.59 \pm 1.866$ \\
\hline
\end{tabular}

Note. Distance traveled values presented as mean \pm SE in meters (m). No significant differences were observed between treatment groups. Analyses performed using Kruskal-Wallis and one-way ANOVA tests. $\left(10 \mathrm{mg} \mathrm{kg}^{-1} \mathrm{n}=8\right.$ vehicle and $\mathrm{n}=13$ diazoxide; 20 $\mathrm{mg} \mathrm{kg}{ }^{-1} \mathrm{n}=9$ vehicle and $\mathrm{n}=19$ diazoxide; $50 \mathrm{mg} \mathrm{kg}^{-1} \mathrm{n}=13$ vehicle and $\mathrm{n}=10$ diazoxide)

\subsection{Histopathology}

H\&E stained sections of brains from all treatment groups provided no evidence of significant histological lesion(s) present for vehicle or diazoxide-treated mice at any level examined (data not shown). In addition, final body weight measurements were performed. Analyses revealed no significant effect of treatment on body weight of same sex animals for any treatment group. In $10 \mathrm{mg}$ $\mathrm{kg}^{-1}$ treatment group $\mathrm{p}=0.8260$ (females) and $\mathrm{p}=0.0780$ (males) (data not shown). For the $20 \mathrm{mg} \mathrm{kg}^{-1}$ treatment group $\mathrm{p}=0.0511$ (females) and $\mathrm{p}=0.3731$ (males; data not shown). The $50 \mathrm{mg} \mathrm{kg}^{-1}$ treatment groups $\mathrm{p}=0.0998$ (female) $\mathrm{p}=0.1714$ (males; data not shown).
Table 2. Total distance traveled in the open field during twelve minute session (Females)

\begin{tabular}{lll}
\hline Treatment & Gender & Distance traveled $(\mathrm{m})$ \\
\hline $\begin{array}{l}\text { Vehicle } \\
\text { Diazoxide } \\
\left(10 \mathrm{mg} \mathrm{kg}^{-1}\right)\end{array}$ & Female & $28.94 \pm 2.359$ \\
$\begin{array}{l}\text { Vehicle } \\
\text { Diazoxide }\end{array}$ & Female & $30.50 \pm 1.663$ \\
$\left(20 \mathrm{mg} \mathrm{kg}^{-1}\right)$ & Female & $39.17 \pm 2.275$ \\
Vehicle & Female & $30.34 \pm 1.524 * * *$ \\
$\begin{array}{l}\text { Diazoxide } \\
\left(50 \mathrm{mg} \mathrm{kg}^{-1}\right)\end{array}$ & Female & $23.66 \pm 2.127$ \\
\hline
\end{tabular}

Note. Distance traveled values presented as mean \pm SE in meters (m). Significant observed in the $20 \mathrm{mg} \mathrm{kg}^{-1}$ treatment group $* * * p<0.001$. Analyses performed using Kruskal-Wallis and one-way ANOVA tests. $\left(10 \mathrm{mg} \mathrm{kg}^{-1} \mathrm{n}=8\right.$ vehicle and $\mathrm{n}=$ 10 diazoxide; $20 \mathrm{mg} \mathrm{kg}^{-1} \mathrm{n}=11$ vehicle and $\mathrm{n}=17$ diazoxide; 50 $\mathrm{mg} \mathrm{kg}^{-1} \mathrm{n}=14$ vehicle and $\mathrm{n}=14$ diazoxide)

\section{DISCUSSION}

This study demonstrates for the first time the long term effect of .chronic neonatal diazoxide therapy. In this study we provide evidence that chronic neonatal administration of diazoxide did not contribute to any changes in physical appearance, sensori-motor skills or working memory. In neuropathological studies, we did not observe any brain abnormalities in any of the mice treated in the neonatal period and examined in adulthood. We recognize that only hematoxylin and eosin was used to stain tissue sections. However, this 
method is a well-recognized neuropathological staining technique and examining thousands of tissue sections, no defects were observed. We also recognize that it is not possible to differentiate whether the lack of neuroantatomical defects, or motor impairments are due to an absence of toxic effects of the treatment or a natural regeneration of the mice. It is important to note that in our in our previous short-term studies, we did not observe any structural brain abnormalities (Fogal et al., 2010). Furthermore, behavioral tests cannot be performed until 9-12 weeks after treatment precluding early testing.

In our experimental conditions, diazoxide-treated mice did not travel significantly greater distances or show a significant difference in their preference for the periphery compare to their vehicle counterparts in the open field. Consequently, we can conclude that diazoxide did not cause modification(s) in spontaneous locomotor activity such as hyperactivity or anxiety-like phenotype. Similarly, no significant differences were detectable in motor coordination and working memory between diazoxide treated mice and their controlcounterparts on the rotarod. Interestingly, females demonstrated better perform on the rotarod, similar results have been shown in another mice strain (Cox et al., 2009). Additionally, we observed that female mice treated with $20 \mathrm{mg} \mathrm{kg}^{-1}$ of diazoxide had better motor coordination and balance than their vehicle-control counterparts. Hyperactivity can not reflect the results exhibited in the rotarod as no hyperactivity was recorded in the open field exploration test. Similar results were not observed with the $50 \mathrm{mg} \mathrm{kg}^{-1}$ group; in fact we see that the vehicle-treated females performed better than their diazoxide-treated counterparts. Suggesting that a threshold was reach in which the addition of more diazoxide did not continue to increase performance.

Diazoxide did not appear to enhance or inhibit swimming abilities or the motivation to escape the water in the Porsolt forced swim test. We demonstrated that chronic neonatal administration of diazoxide significantly increased duration of immobility in diazoxide-treated females $\left(10 \mathrm{mg} \mathrm{kg} \mathrm{kg}^{-1}\right)$. These results provide evidence for the involvement of $\mathrm{K}_{\mathrm{ATP}}$ channels in the induction of depressive-like phenotype. Our results correlate with previous studies that demonstrated this antiimmobility effect of various $\mathrm{K}_{\mathrm{ATP}}$ channel openers in the forced swim test (Galeotti et al., 1999; Redrobe et al., 1996). In addition, our data is the first to illustrate gender-specific involvement of KATP channel openers influence on immobility. Taken as a whole, our results would suggest that KATP channels functionally appear to be fundamental in the modulation of motor coordination and immobility.

The observed depressive-like phenotype may reflect the hypothesis that KATP channel openers cause hyperpolarization of neurons. One study revealed that KATP channel opener, diazoxide effectively depressed the excitability of the CA1 interneuron (Griesemer et al., 2002). In addition, this study showed that diazoxide altered the resting membrane potential producing hyperpolarization in three types of hippocampal neurons (Griesemer et al., 2002). However, diazoxide had no effect on the amplitude of the action potential (Griesemer et al., 2002). Therefore one may conclude that the reason for the depressive effects we observed by the chronic neonatal administration of diazoxide is because the neurons have a more negative resting membrane potential.

\section{CONCLUSION}

In summary, we find that chronic neonatal diazoxide therapy does not enhance or cause long term deficits to neurological functions, motor function or learning and memory enhancements in mouse behavior. However, diazoxide may induce depressivelike phenotypes in females. Diazoxide does not cause changes in gross anatomy and histology of the brain. As such, these studies provide important preclinical data for potential future studies aimed at assessing the potential clinical utility of diazoxide.

\section{ACKNOWLEDGEMENT}

This research was supported in part from grants from National Institute of Health (3R01NS06803902S1) and National Institute of Neurological Disorders and Stroke (S068039). Some of the data from the paper were previously presented at the annual meeting of the Society for Neuroscience in New Orleans (October 2012). Authors do not have any interests that might be interpreted as influencing the research and APA ethical standards were followed in conducting the study. It is a pleasure to thank Sarah Renzi for her technical assistance with this study.

\section{REFERENCES}

Ashcroft, S.J. and F.M. Ashcroft, 1990. Properties and functions of ATP-sensitive K-channels. Cell Single, 2:197-214. PMID: 2119205 
Babenko, A.P., L., Aguilar-Bryan and J. Bryan, 1998. A view of SUR/KIR6.X, KATP channels. Annual Rev. Physiol., 60: 667-687. DOI: 10.1146/annurev.physiol.60.1.667

Babenko, A.P., G. Gonzalez and J. Bryan, 2000. Pharmaco-topology of sulfonylurea receptors: Separate domanins of the regulatory subunits of $\mathrm{K}$ channel is forms are required for selective interaction with $\mathrm{K}+$ channel openers. J. Biol. Chem., 275: 717-720. DOI: 10.1074/jbc.275.2.717

Back, S.A. and S.A. Rivkees, 2004. Emerging concepts in periventricular white matter injury. Seminars Perinatol., 28: 405-414. DOI: 10.1053/j.semperi.2004.10.010

Baines, C.P., G.S. Liu, M. Birincioglu, Critz and S.D., Cohen et al., 1999. Ischemic preconditioning depends on interaction between mitochondrial KATP channels and actin cytoskeleton. Am. J. Physiol., 276: H1361-1368.

Cox, M.M., A.M. Tucker, J. Tang, K. Talbot and D.C. Richer et al., 2009. Neurobehavioral abnormalities in the dysbindin-1 mutant, sandy, on a genetic background. Genes, Brain Behav., 8: 390-397. DOI: 10.1111/j.1601-183X.2009.00477.x

Craig, A., N.L. Luo, D.J Beardsley, N., Wingate-Pearse and D.W. Walker, 2003. Quantitative analysis of perinatal rodent oligodendrocyte lineage progression and its correlation with human. Exp. Neurol., 181: 231-240. PMID: 12781996

Fogal, B., C. McClaskey, S. Yan, H. Yan and S.A. Rivkees, 2010. Diazoxide promotes oligodendrocyte precursor cell proliferation and myelination. Plos One, 5: E10906-E10906. DOI: 10.1371/journal.pone.0010906

Galeotti, N., C. Ghelardini, B. Caldari and A. Bartolini, 1999. Effect of potassium channel modulators in mouse forced swimming test. British J. Pharmacol., 126: 1653-1659. DOI: 10.1038/sj.bjp.0702467

Goodman, Y. and M.P. Mattson, 1996. K+ channel openers protect hippocampal neurons against oxidative injury and amyloid beta-peptide toxicity. Brain Res., 706: 328-332. DOI: 10.1016/00068993(95)01367-9

Griesemer, D., C. Zawar and B. Neumcke, 2002. Celltype specific depression of neuronal excitability in rat hippocampus by activation of ATP-sensitive potassium channels. Eur. Biophys., J. 31: 467-477. DOI: $10.1007 / \mathrm{s} 00249-002-0241-3$
Liu, D., J.R. Slevin, C. Lu, S.L. Chan and M. Hansson et al., 2003. Involvement of mitochondrial $\mathrm{K}+$ release and cellular efflux in ischemic and apoptotic neuronal death. J. Neurochem., 86: 966-979. PMID: 12887694

Lui, C.Y., F.I Marcus and R.E Sobonya, 2002. Arrhythmogenic right ventricular dysplasia masquerading as peripartum cardiomyopathy with atrial flutter, advanced atrioventricular block and embolic stroke. Cardiology, 97: 49-50. DOI: 10.1159/000047419

Murata, M., M. Akao, B. O’Rourke and E. Marban, 2001. Mitochondrial ATP-sensitive potassium channels attenuate matrix $\mathrm{Ca}(2+)$ overload during simulated ischemia and reperfusion: Possible mechanism of cardioprotection. Circ. Res., 89: 891-898. PMID: 11701616

Porsolt, R.D., A. Bertin and M. Jalfre, 1977. Behavioral despair in mice: A primary screening test for antidepressants. Archives Int. de pharmacodynamie et de therapie, 229: 327-336. PMID: 596982

Redrobe, J.P., P. Pinot and M. Bourin, 1996. The effect of the potassium channel activator, cromakalim, on antidepressant drugs in the forced swimming test in mice. Fundamental Clin. Pharmacol., 10: 524-528. DOI: $10.1111 /$ j.1472-8206.1996.tb00610.x

Takashi, E., Y. Wang and M. Ashraf, 1999. Activation of mitochondrial $\mathrm{K}$ (ATP) channel elicits late preconditioning against myocardial infarction via protein kinase $\mathrm{C}$ signaling pathway. Circ. Res., 85: 1146-1153. DOI: 10.1161/01.RES.85.12.1146

Wang, L., Q.L. Zhu, G.Z. Wang, T.Z. Deng and R. Chen et al., 2011. The protective roles of mitochondrial ATP-sensitive potassium channels during hypoxiaischemia-reperfusion in brain. Neurosci. Lett., 491: 63-67. DOI: 10.1016/j.neulet.2010.12.065

Zaugg, M., E. Lucchinetti, D.R. Spahn, T. Pasch and C. Garcia et al., 2002. Differential effects of anesthetics on mitochondrial K (ATP) channel activity and cardiomyocyte protection. Anesthesiology, 97: 15-23. DOI: 10.1097/00000542-200207000-00004 